\title{
Diabetes Mellitus in Outpatients in Debre Berhan Referral Hospital, Ethiopia
}

\author{
Tesfa Dejenie Habtewold, ${ }^{1}$ Wendwesen Dibekulu Tsega, ${ }^{2}$ and Bayu Yihun Wale ${ }^{1}$ \\ ${ }^{1}$ College of Health Science, Department of Nursing, Debre Berhan University, 445 Debre Berhan, Ethiopia \\ ${ }^{2}$ College of Health Science, Department of Public Health, Debre Berhan University, 445 Debre Berhan, Ethiopia \\ Correspondence should be addressed to Tesfa Dejenie Habtewold; tesfadej2003@gmail.com
}

Received 29 August 2015; Revised 26 November 2015; Accepted 30 November 2015

Academic Editor: Marco Songini

Copyright (c) 2016 Tesfa Dejenie Habtewold et al. This is an open access article distributed under the Creative Commons Attribution License, which permits unrestricted use, distribution, and reproduction in any medium, provided the original work is properly cited.

\begin{abstract}
Introduction. Diabetes mellitus is a group of metabolic diseases characterized by hyperglycemia resulting from defects in insulin secretion, insulin action, or both. Most people with diabetes live in low- and middle-income countries and these will experience the greatest increase in cases of diabetes over the next 22 years. Objective. To assess the prevalence and associated factors of diabetes mellitus among outpatients of Debre Berhan Referral Hospital. Methods and Materials. A cross-sectional study was conducted from April to June 2015 among 385 patients. Random quota sampling technique was used to get individual patients and risk factors assessment. Patients diabetes status was ascertained by World Health Organization Diabetes Mellitus Diagnostic Criteria. The collected data were entered, cleaned, and analyzed and Chi-square test was applied to test any association between dependent and independent variable. Result. Out of the total 385 study patients, 368 have participated in the study yielding a response rate of 95.3\%. Concerning clinical presentation of diabetes mellitus, $13.3 \%$ of patients reported thirst, $14.4 \%$ of patients declared polyurea, and $14.9 \%$ of patients ascertained unexplained weight loss. The statistically significant associated factors of diabetes mellitus were hypertensive history, obesity, the number of parities, and smoking history. Conclusion. The prevalence of diabetes mellitus among outpatients in Debre Berhan Referral Hospital was $0.34 \%$ and several clinical and behavioral factors contribute to the occurrence of diabetes mellitus which impose initiation of preventive, promotive, and curative strategies.
\end{abstract}

\section{Introduction}

Diabetes mellitus is a group of metabolic diseases characterized by chronic hyperglycemia resulting from defects in insulin secretion, insulin action, or both. It is classified as type 1 diabetes, type 2 diabetes, gestational diabetes, and other types of diabetes mellitus [1]. Diabetes mellitus is the most common chronic disease among adults. The global burden of diabetes has increased twelvefold between 1985 and 2011 [2].

In 2013, 382 million people had diabetes; this number is expected to rise to 592 million by 2035 . Most people with diabetes live in low- and middle-income countries and these will experience the greatest increase in cases of diabetes over the next 22 years $[3,4]$. According to the international diabetes federation 2013 reports, in North America and Caribbean countries 1 in 10 adults has diabetes; in Southern and Western America 1 in 11 adults has diabetes. Similarly, in Europe 21-22 million people have diabetes [5]. Moreover, in
2013, the number of people with diabetes is estimated to be 56 million in Europe with an overall estimated prevalence of $8.5 \%$. However, estimates of diabetes prevalence in 2013 vary widely in the 56 diverse countries in Europe from $2.4 \%$ in Moldova to $14.9 \%$ in Turkey [6].

On the contrary in 2010, 12.1 million people were to be living with diabetes mellitus in Africa and over the next 20 years the number of people with diabetes will almost double $[2,7,8]$. Based on the IDF Diabetes Atlas 2014 update the agestandardized prevalence of diabetes in the Middle East and North Africa was estimated at $10.9 \%$ and projected to increase to $11.3 \%$ by 2035 [9]. Additionally, a systematic review by Bos and Agyemang revealed that the prevalence of diabetes varied across Northern African countries ranging from 2.6\% in rural Sudan to $20 \%$ in urban Egypt. Ten studies distinguished between urban and rural diabetes prevalence and all of these studies found a higher prevalence in urban areas than in rural areas [10]. 
According to 2011 reports of the International Diabetes Federation (IDF), the number of adults living with diabetes in Ethiopia was 3.5\% [11]. Even though the national prevalence of diabetes in Ethiopia is estimated to be $2 \%$, evidence suggests that its prevalence could be more than 5\% in those older than 40 years of age in some setting [12-14]. A study by Watkins and Alemu conducted in Gondar found out most of the rural patients (77\%) had type 1 diabetes whereas in urban areas only $29 \%$ had type 1 and $71 \%$ of them type 2 diabetes [15]. Generally, the global burden of diabetes mellitus has been increasing radically. The impact is high especially in developing countries in which resource is limited to identify the problem and develop need based clinical and community intervention. Therefore, the objective of this study was to assess the prevalence and associated factors of diabetes mellitus among outpatients of Debre Berhan Referral Hospital.

\section{Methods and Materials}

2.1. Study Setting. Debre Berhan is the capital city of North Shoa, one of the 13 zones of Amhara regional state which is located $130 \mathrm{KM}$ north of Addis Ababa, Ethiopia. The foundation of the town was traced back to the regime of Atse Zereyakob. Regarding health services in the city, there are one government and one private hospital, two government health centers, five health posts, and 18 private clinics. Debre Berhan Referral Hospital is the only government hospital in the city and it is zonal referral hospital serving the population of the zone as a referral center and the place where this study was conducted [16].

2.2. Study Design and Population. A cross-sectional study was conducted from April to June 2015 among 385 patients who visited the outpatient department of Debre Berhan Referral Hospital. All outpatients who visited the hospital during the data collection period were included. Nevertheless, patients who were severely ill, not cooperative, having difficulty in hearing, and visual impairment were excluded. The hospital has many units organized to render care for clients. From these units outpatient units 1, 2, 3, and 5, dental clinic, pediatrics outpatient unit 1 , and maternal health unit were selected using simple random sampling technique. To reach individual patients, random quota sampling technique was used.

2.3. Data Collection Tools and Procedures. The questionnaire has three parts: sociodemographic characteristics, WHO Diabetes Mellitus Diagnostic Criteria [17], and associated risk factors assessment. The patients' diabetes status was ascertained by considering two classic clinical symptoms and laboratory test of random blood glucose level. To classify diabetes mellitus into type 1 , type 2 , and gestational, classic symptoms and signs, the age of the patient, random blood sugar level, and pregnancy status were used as a criterion. The data were collected by internship nursing students and professional nurses in selected unit using pretested, structured interviewer administered questionnaire. Also, the standard "forward-backward" procedure was applied to translate the questionnaire from English into Amharic. To ensure data quality, orientation was given for all patients, data collectors were trained, and appropriate study design and sampling technique were deliberated. Additionally, a pretest was done on $5 \%$ of respondents. The data was entered, cleaned, and analyzed. Chi-square test was applied to test any association between dependent and independent variable using significance level $(\alpha)$ 0.05. To calculate the exact $p$ value, Social Science Statistics $p$ value calculator was used [18]. Fisher's exact test was also used when the chi-square test assumption was not fulfilled. Finally, the result was presented using descriptive statement, table, and figure.

2.4. Ethical Consideration. This study was done in conformity with the ethical guidelines approved by the Institute of Medicine and Health Science of Debre Berhan University. By explaining objectives of the study and its significance, relevant permission was obtained from hospital administration office. At individual level verbal consent was obtained from all patients.

\section{Result}

3.1. Sociodemographic Characteristics. Out of the total 385 study participants, 368 have participated in the study yielding a response rate of $95.32 \%$. As described in Table 1, among the patients more than half $(53.26 \%)$ of them were females. The majority of respondents $(30.98 \%)$ were in the age group of $<30$. Additionally, most of the study subjects $(74.45 \%)$ were Amhara and $70.10 \%$ were married. Moreover, $27.44 \%$ of the patients were illiterate.

3.2. Diagnostic Criteria of Diabetes Mellitus. As shown in Table 2, $13.32 \%$ of patients reported polydipsia, $14.40 \%$ of patients declared polyuria, and $14.94 \%$ of patients reported unexplained weight loss. Similarly, $7.07 \%$ of the patients had random blood sugar $\geq 200 \mathrm{mg} / \mathrm{dL}$. Based on these criteria the overall prevalence of diabetes mellitus in Debre Berhan Referral Hospital was $0.34 \%$.

3.3. Factors Associated with Diabetes Mellitus. As revealed in Table 3, 6.52\% of the respondents had a family history of diabetes mellitus, $2.72 \%$ were twins, and $5.43 \%$ had previously known hypertensive disease. Also, most of (82.07\%) patients did not do regular physical exercise.

As shown in Figure 1, among those diabetes cases, 4 cases (15.4\%) were diagnosed as type 1 diabetes mellitus, $80.77 \%$ were type 2 DM, 3.85\% were gestational type of diabetes mellitus.

As portrayed in Figure 2, 15.4\% of the diabetes cases were found in the age group of $<30 ; 30.77 \%$ of the diabetes cases were found in the age group of $30-39$; the other $23.07 \%$ of them were found in the age group of $40-49$; and about $30.77 \%$ of the diabetes cases were found in the age group of $\geq 50$.

Concerning nonclassical symptoms and signs, $15.4 \%$ had reported a loss of consciousness, $46.15 \%$ reported developing numbness and tingling sensation, $42.3 \%$ have blurred vision, and the other $15.4 \%$ have reported wounds that cannot heal easily. Furthermore, among the diabetes cases, $23 \%$ of them had a history of hypertension. 
TABLE 1: Sociodemographic characteristics of patients in Debre Berhan Referral Hospital in June 2015.

\begin{tabular}{|c|c|c|c|}
\hline Variables & Categories & Frequency & Percentage \\
\hline \multirow{2}{*}{ Sex } & Male & 172 & 46.74 \\
\hline & Female & 196 & 53.26 \\
\hline \multirow{4}{*}{ Age } & $<30$ & 114 & 30.98 \\
\hline & $30-39$ & 112 & 30.43 \\
\hline & $40-49$ & 77 & 20.92 \\
\hline & $>50$ & 65 & 17.67 \\
\hline \multirow{4}{*}{ Ethnicity } & Amhara & 274 & 74.45 \\
\hline & Tigray & 24 & 6.53 \\
\hline & Oromia & 66 & 17.93 \\
\hline & Other & 4 & 1.09 \\
\hline \multirow{4}{*}{ Religion } & Orthodox & 271 & 73.64 \\
\hline & Muslim & 63 & 17.12 \\
\hline & Catholic & 6 & 1.63 \\
\hline & Protestant & 28 & 7.61 \\
\hline \multirow{4}{*}{ Marital status } & Married & 258 & 70.10 \\
\hline & Single & 72 & 19.56 \\
\hline & Divorced & 16 & 4.35 \\
\hline & Widowed & 22 & 5.99 \\
\hline \multirow{5}{*}{$\begin{array}{l}\text { Educational } \\
\text { status }\end{array}$} & Illiterate & 100 & 27.17 \\
\hline & Can read and write & 76 & 20.65 \\
\hline & Grade 1 to grade 8 & 63 & 17.12 \\
\hline & Grade 9 to grade 12 & 54 & 14.67 \\
\hline & Diploma and above & 75 & 20.65 \\
\hline \multirow{5}{*}{$\begin{array}{l}\text { Occupational } \\
\text { status }\end{array}$} & Government employed & 76 & 20.65 \\
\hline & Self-employed & 90 & 24.45 \\
\hline & Merchant & 42 & 11.41 \\
\hline & Housewife & 87 & 23.64 \\
\hline & Others & 73 & 19.84 \\
\hline \multirow{3}{*}{$\begin{array}{l}\text { Monthly } \\
\text { income status }\end{array}$} & $\leq 650$ & 189 & 51.36 \\
\hline & $651-1400$ & 75 & 20.38 \\
\hline & $\geq 1401$ & 104 & 28.26 \\
\hline
\end{tabular}

3.4. Statistical Test. As observed from Table 4, the $p$ value of family history of diabetes mellitus and twin delivery was greater than 0.05 , consequently interpreted as there is no association of family history of diabetes mellitus and twin delivery with the occurrence of diabetes mellitus. On the other hand, hypertensive history, obesity, number of parities, and smoking history have direct association with the occurrence of diabetes mellitus. Among those associated factors hypertensive history has the highest contribution following the number of parities and obesity.

\section{Discussion}

To our knowledge, this study was the first in Debre Berhan. It was conducted with the aim of assessing the prevalence and associated factors of diabetes mellitus.
TABLE 2: WHO diagnostic criteria to know diabetes mellitus status of patients in Debre Berhan Referral Hospital in June 2015.

\begin{tabular}{|c|c|c|}
\hline Variables & Frequency & Percentage \\
\hline \multicolumn{3}{|c|}{ Classic symptoms } \\
\hline \multicolumn{3}{|l|}{ Thirst } \\
\hline Yes & 49 & 13.32 \\
\hline No & 319 & 86.68 \\
\hline \multicolumn{3}{|c|}{ Polyuria } \\
\hline Yes & 53 & 14.40 \\
\hline No & 311 & 84.51 \\
\hline \multicolumn{3}{|c|}{ Unexplained weight loss } \\
\hline Yes & 55 & 14.94 \\
\hline No & 313 & 85.06 \\
\hline \multicolumn{3}{|c|}{ Classic sign } \\
\hline \multicolumn{3}{|c|}{$\mathrm{RBS} \geq 200 \mathrm{mg} / \mathrm{dL}$} \\
\hline Yes & 26 & 7.07 \\
\hline No & 342 & 92.93 \\
\hline \multicolumn{3}{|l|}{ Others } \\
\hline \multicolumn{3}{|l|}{ Fatigue } \\
\hline Yes & 161 & 43.75 \\
\hline No & 207 & 56.25 \\
\hline \multicolumn{3}{|c|}{ Nausea and vomiting } \\
\hline Yes & 84 & 22.83 \\
\hline No & 284 & 77.59 \\
\hline \multicolumn{3}{|c|}{ Polyphagia } \\
\hline Yes & 23 & 6.25 \\
\hline No & 345 & 93.75 \\
\hline \multicolumn{3}{|c|}{ Headache } \\
\hline Yes & 148 & 40.22 \\
\hline No & 220 & 59.78 \\
\hline \multicolumn{3}{|c|}{ Loss of consciousness } \\
\hline Yes & 15 & 4.08 \\
\hline No & 353 & 95.92 \\
\hline \multicolumn{3}{|c|}{ Numbness and tingling sensation } \\
\hline Yes & 45 & 12.23 \\
\hline No & 323 & 87.77 \\
\hline \multicolumn{3}{|c|}{ Blurring of vision } \\
\hline Yes & 34 & 9.24 \\
\hline No & 334 & 90.76 \\
\hline
\end{tabular}

In this study the percentage of diabetes mellitus among children $\leq 14$ years was about $3.85 \%$. Differently in a study by the World Health Organization's multinational project for childhood initially reported in 2000 the prevalence was 19,164 cases from the population of 75.1 million people which are about $0.025 \%$ [19]. This difference might be due to variation in sample size. Also, in this study the percentage of type 1 diabetes mellitus was about $15.4 \%$; however, a decreased prevalence of $4 \%$ of type 1 diabetes mellitus was observed in the population studied in Asia, about 3.2\% in Europe and $5.3 \%$ in North America [20]. This might be due to the lifestyle difference between Ethiopia and Western countries.

Furthermore, we found out the frequency of type 1 diabetes was not high in the youngest age group ( $0-4$ years) 
TABle 3: Associated factors among patients in Debre Berhan Referral Hospital in June 2015.

\begin{tabular}{lcc}
\hline Variables & Frequency & Percentage \\
\hline Family history of diabetes mellitus & & \\
$\quad$ Yes & 24 & 6.52 \\
$\quad$ No & 344 & 93.48 \\
Twin delivery & & \\
$\quad$ Identical & 5 & 1.36 \\
$\quad$ Fraternal & 5 & 1.36 \\
Previously hypertensive disease & & \\
$\quad$ Yes & 20 & 5.43 \\
$\quad$ No & 348 & 94.57 \\
Activity and exercise & & \\
$\quad$ Good & 302 & 82.07 \\
$\quad$ Poor & 66 & 17.03 \\
Obesity $(\mathrm{BMI})$ & & \\
$\quad \leq 24.9 \mathrm{~kg} / \mathrm{m}^{2}$ & 340 & 92.39 \\
$\quad>24.9 \mathrm{~kg} / \mathrm{m}^{2}$ & 28 & 7.61 \\
Number of children delivered & & \\
$\quad<2$ times & 71 & 19.29 \\
$\quad \geq 2$ times & 61 & 16.58 \\
$\quad$ No & 33 & 8.97 \\
\hline
\end{tabular}

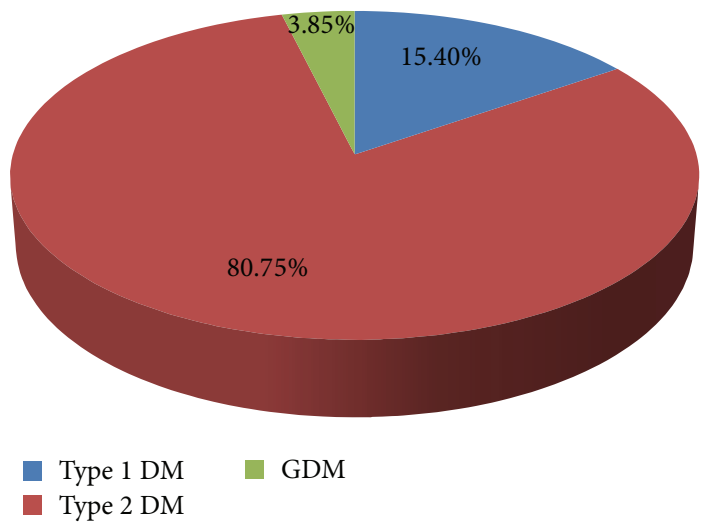

Figure 1: Diabetes mellitus category of patients in Debre Berhan Referral Hospital in June 2015.

and the percentage increased (15.4\%) after puberty and young adulthood (15-29 years). On the contrary, a study done in Europe suggests that the prevalence rate of type $1 \mathrm{DM}$ was highest in the youngest age group ( $0-4$ years) and prevalence rates decline after puberty and appear to stabilize in young adulthood (15-29 years) [21]. This might be due to the difference in feeding habit, knowledge and health seeking behavior, and living standard.

In addition, in this study the percentage of type 2 diabetes mellitus was $80.77 \%$ but a ten-year observation at Gondar University Teaching Referral Hospital found out $49.9 \%$ were type 2 DM [22] and the prevalence study in Jimma University stated that $66.2 \%$ of the respondents were medically diagnosed as having type 2 diabetes mellitus [23].

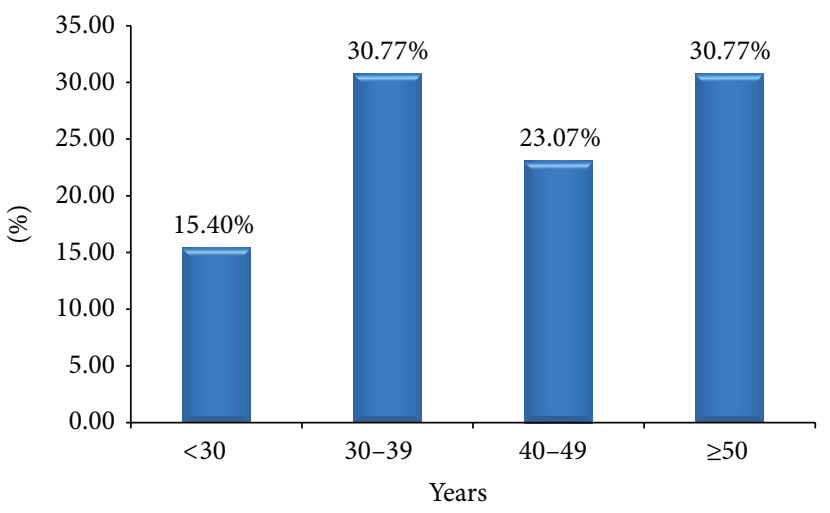

FIGURE 2: Distribution of diabetes mellitus among different age groups of patients in Debre Berhan Referral Hospital in June 2015.

This difference might be due to the difference in the duration of time of the study to conclude for the general population.

Concerning associated factors, numerous epidemiological studies were conducted to discriminate the different associated factors. In this study, there is no significant association between family history of diabetes mellitus and the occurrence of diabetes mellitus but a study done on the Palestinians, Iranians, and Kuwaitis documented that family history of diabetes increased the risk of the incidence by 1.6, 1.8, and 2.4 times, respectively [24-26]. In our study, however, the increased body mass index was also one of significant risk factors. This finding was consistent with WHO STEPS report [27], the study done in Israel [28] and Iran and Jordan [29]. Moreover, smoking history was a significant risk factor. This finding was in line with the study conducted in European countries [6]. Other significant risk factors of diabetes mellitus, not assessed in this study (but future researchers should consider them), are elevated triglycerides, total cholesterol, and low HDL cholesterol [30], gender and educational status [24], socioeconomic status [31], and physical inactivity $[6,27,32,33]$.

\section{Strength and Limitation}

The strengths of this study include a high response rate and the inclusive nature of this research as individuals could participate regardless of their demographic variation. Additionally, a reasonable sample size and culturally adapted questionnaires were used. Since it was the first study in Debre Berhan, it will provide basic information for those who have an interest. Furthermore, objective laboratory data were used to ascertain disease status of patients.

Despite these strengths, this study contains the following limitations: since the study was institutional and conducted among outpatients in only one hospital it could limit our understanding regarding the prevalence and associated factors of diabetes mellitus in the setting. Even though data collectors were blind for the study subjects, there might be selection bias. Moreover, due to cross-sectional nature of the study causal relationships between the risk factors and disease outcome could not be assumed. Furthermore, the data was 
TABLE 4: Statistical test for associated factors of diabetes mellitus in Debre Berhan Referral Hospital in June 2015.

\begin{tabular}{|c|c|c|c|c|}
\hline Variables & Calculated chi-square value & Degree of freedom & Odds ratio & $p$ value \\
\hline Family history of diabetes mellitus & 3.6 & 1 & 2.9 & 0.06 \\
\hline Previous history of hypertension & 25.25 & 1 & 9.3 & 0.000 \\
\hline Body mass index & 9.33 & 1 & 4.36 & 0.002 \\
\hline Parity & 11.34 & 1 & 8.95 & 0.0008 \\
\hline Twin delivery & 0.2 & 1 & 1.46 & 0.65 \\
\hline Smoking history & 5.45 & 1 & 4.33 & 0.02 \\
\hline
\end{tabular}

analyzed manually and chi-square model which was a weak measure of association was utilized.

\section{Conclusion}

Diabetes mellitus and other noncommunicable diseases are becoming abundant in developing countries including Ethiopia due to lack of problem identification and intervention of these problems.

This study is targeted to know the prevalence of diabetes mellitus among outpatients in Debre Berhan Referral Hospital and associated factors that contribute to the occurrence of diabetes mellitus accompanied by initiation of preventive, promotive, and curative strategies.

Moreover, the study will help to initiate the community, health institution, and other concerned nongovernmental organizations to give emphasis to the population for controlling of diabetes mellitus. It will also give baseline information for those who aim to conduct a community-based longitudinal research in this area. Finally, mass media, zonal health office, and the Ministry of Health should work on the use of evidence-based medicine and awareness creation by developing an up-to-date guideline tailored to each specific group of the population.

\section{Abbreviations}

BMI: Body mass index

CBE: Community-based education

DBRH: Debre Berhan Referral Hospital

DBU: Debre Berhan University

DM: $\quad$ Diabetes mellitus

ETB: Ethiopian birr

GDM: Gestational diabetes mellitus

IDDM: Insulin dependent diabetes mellitus

IDF: International diabetes federation

OPD: Outpatient department

PI: $\quad$ Principal investigator

SSB: $\quad$ Sugar sweetened beverage

$\mathrm{T}_{1}$ DM: Type 1 diabetes mellitus

$\mathrm{T}_{2}$ DM: Type 2 diabetes mellitus

UKDPS: United Kingdom diabetes prospective study

WHO: World Health Organization.

\section{Conflict of Interests}

The authors declare that they have no competing interests.

\section{Authors' Contribution}

Bayu Yihun Wale conceived of the study and participated in its design. Tesfa Dejenie Habtewold participated in design and coordination of the study. Wendwesen Dibekulu Tsega helped to draft the paper. All authors read and approved the final paper.

\section{Acknowledgments}

The authors would like to thank Debre Berhan University, Department of Nursing, for creating this chance. Additionally, They would like to forward their special acknowledgment to Alelign Wondim, Bizualem Lemma, Ejinsu Yizezew, and Tsgie Gebretsadik who had a crucial role during data collection and analysis of the data. The authors' recognition also goes to Debre Berhan Referral Hospital officials, Sr. Tseganesh Biyabil (Matron Nurse) and Dr. Feseha Tadesse (Medical Director), who facilitated the data collection. The authors' heartfelt gratitude and high appreciation also go to patients who were willing to take part in the study.

\section{References}

[1] A. T. Kharroubi and H. M. Darwish, "Diabetes mellitus: the epidemic of the century," World Journal of Diabetes, vol. 6, no. 6, pp. 850-867, 2015.

[2] J. E. Shaw, R. A. Sicree, and P. Z. Zimmet, "Global estimates of the prevalence of diabetes for 2010 and 2030," Diabetes Research and Clinical Practice, vol. 87, no. 1, pp. 4-14, 2010.

[3] L. Guariguata, D. R. Whiting, I. Hambleton, J. Beagley, U. Linnenkamp, and J. E. Shaw, "Global estimates of diabetes prevalence for 2013 and projections for 2035," Diabetes Research and Clinical Practice, vol. 103, no. 2, pp. 137-149, 2014.

[4] T. A. Harrison, L. A. Hindorff, H. Kim et al., "Family history of diabetes as a potential public health tool," American Journal of Preventive Medicine, vol. 24, no. 2, pp. 152-159, 2003.

[5] International Diabetes Federation, Diabetes ATLAS, Updated, 5th edition, 2013, http://www.idf.org/sites/default/files/MediaInformation-Pack.pdf.

[6] T. Tamayo, J. Rosenbauer, S. H. Wild et al., "Diabetes in Europe: an update," Diabetes Research and Clinical Practice, vol. 103, no. 2, pp. 206-217, 2014.

[7] World Health Organization, The Global Burden of Disease, World Health Organization, Geneva, Switzerland, 2004, http:// www.who.int/healthinfo/global_burden_disease/2004_report_ update/en/. 
[8] R. Sicree, J. Shaw, and P. Zimmet, "The global burden: diabetes and impaired glucose tolerance," April 2015, https://www.idf .org/sites/default/files/Diabetes\%20and\%20Impaired\%20Glucose $\% 20$ Tolerance_1.pdf.

[9] A. Majeed, A. A. El-Sayed, T. Khoja, R. Alshamsan, C. Millett, and S. Rawaf, "Diabetes in the Middle-East and North Africa: an update," Diabetes Research and Clinical Practice, vol. 103, no. 2, pp. 218-222, 2014.

[10] M. Bos and C. Agyemang, "Prevalence and complications of diabetes mellitus in Northern Africa, a systematic review," BMC Public Health, vol. 13, no. 1, article 387, 2013.

[11] D. R. Whiting, L. Guariguata, C. Weil, and J. Shaw, "IDF Diabetes Atlas: global estimates of the prevalence of diabetes for 2011 and 2030," Diabetes Research and Clinical Practice, vol. 94, no. 3, pp. 311-321, 2011.

[12] L. D. Nshisso, A. Reese, B. Gelaye, S. Lemma, Y. Berhane, and M. A. Williams, "Prevalence of hypertension and diabetes among Ethiopian adults," Diabetes and Metabolic Syndrome, vol. 6, no. 1, pp. 36-41, 2012.

[13] S. Alemu, A. Dessie, E. Seid et al., "Insulin-requiring diabetes in rural Ethiopia: should we reopen the case for malnutritionrelated diabetes?" Diabetologia, vol. 52, no. 9, pp. 1842-1845, 2009.

[14] G. V. Gill, J.-C. Mbanya, K. L. Ramaiya, and S. Tesfaye, "A subSaharan African perspective of diabetes," Diabetologia, vol. 52, no. 1, pp. 8-16, 2009.

[15] P. Watkins and S. Alemu, "Delivery of diabetes care in rural Ethiopia: an experience from Gondar," Ethiopian Medical Journal, vol. 41, no. 1, pp. 9-17, 2003.

[16] Ministry of Urban Development and Construction, Debre Berhan City Administration, December 2015, http://www.mwud .gov.et/web/debreberehan/home.

[17] Diagnostic Criteria for Diabetes World Health Organisation (WHO) Recommendations, 2015, https://www.diabetes.org.uk/ About_us/What-we-say/Diagnosis-ongoing-management-monitoring/New_diagnostic_criteria_for_diabetes/.

[18] J. Stangroom, "Social Science Statistics: p-Value from ChiSquare Calculator," 2015, http://www.socscistatistics.com/pvalues/chidistribution.aspx.

[19] M. Karvonen, M. Viik-Kajander, E. Moltchanova, I. Libman, R. LaPorte, and J. Tuomilehto, "Incidence of childhood type 1 diabetes worldwide. Diabetes Mondiale (DiaMond) Project Group," Diabetes Care, vol. 23, no. 10, pp. 1516-1526, 2000.

[20] DIAMOND Project Group, "Prevalence and trends of childhood type 1 diabetes worldwide 1990-1999," Diabetic Medicine, vol. 23, no. 8, pp. 857-866, 2006.

[21] EURODIAB ACE Study Group, "Variation and trends in incidence of childhood diabetes in Europe," The Lancet, vol. 355, no. 9207, pp. 873-876, 2000.

[22] S. M. Abebe, Y. Berhane, A. Worku, and S. Alemu, "Increasing trends of diabetes mellitus and body weight: a ten year observation at Gondar university teaching referral hospital, northwest Ethiopia," PLoS ONE, vol. 8, no. 3, Article ID e60081, 2013.

[23] K. Ayele, B. Tesfa, L. Abebe, T. Tilahun, and E. Girma, "Self care behavior among patients with diabetes in Harari, eastern Ethiopia: the health belief model perspective," PLOS ONE, vol. 7, no. 4, Article ID e35515, 2012.

[24] H. Harati, F. Hadaegh, N. Saadat, and F. Azizi, "Populationbased incidence of Type 2 diabetes and its associated risk factors: results from a six-year cohort study in Iran," BMC Public Health, vol. 9, article 186, 2009.
[25] H. S. A. Mousa, S. Yousef, F. Riccardo, W. Zeidan, and G. Sabatinelli, "Hyperglycaemia, hypertension and their risk factors among Palestine refugees served by UNRWA," Eastern Mediterranean Health Journal, vol. 16, no. 6, pp. 609-614, 2010.

[26] M. A. A. Moussa, M. Alsaeid, T. M. K. Refai, N. Abdella, N. AlSheikh, and J. E. Gomez, "Factors associated with type 1 diabetes in Kuwaiti children," Acta Diabetologica, vol. 42, no. 3, pp. 129137, 2005.

[27] World Health Organization STEPS country reports, 2015, http:// www.who.int/chp/steps/reports/en/.

[28] A. Tirosh, I. Shai, A. Afek et al., "Adolescent BMI trajectory and risk of diabetes versus coronary disease," The New England Journal of Medicine, vol. 364, no. 14, pp. 1315-1325, 2011.

[29] M. Zindah, A. Belbeisi, H. Walke, and A. H. Mokdad, "Obesity and diabetes in Jordan: findings from the behavioral risk factor surveillance system, 2004," Preventing Chronic Disease, vol. 5, no. 1, article A17, 2008.

[30] K. M. V. Narayan, J. P. Boyle, T. J. Thompson, E. W. Gregg, and D. F. Williamson, "Effect of BMI on lifetime risk for diabetes in the U.S," Diabetes Care, vol. 30, no. 6, pp. 1562-1566, 2007.

[31] M. Maddah, "Association of diabetes with living area in Iranian women," International Journal of Cardiology, vol. 143, no. 1, pp. 100-102, 2010.

[32] V. R. Collins, G. K. Dowse, P. M. Toelupe et al., "Increasing prevalence of NIDDM in the Pacific Island population of Western Samoa over a 13-year period," Diabetes Care, vol. 17, no. 4, pp. 288-296, 1994.

[33] S. T. Win Tin, C. M. Y. Lee, and R. Colagiuri, "A profile of diabetes in Pacific island countries and territories," Diabetes Research and Clinical Practice, vol. 107, no. 2, pp. 233-246, 2015. 


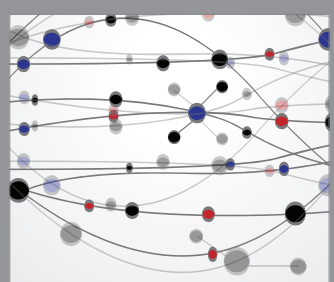

The Scientific World Journal
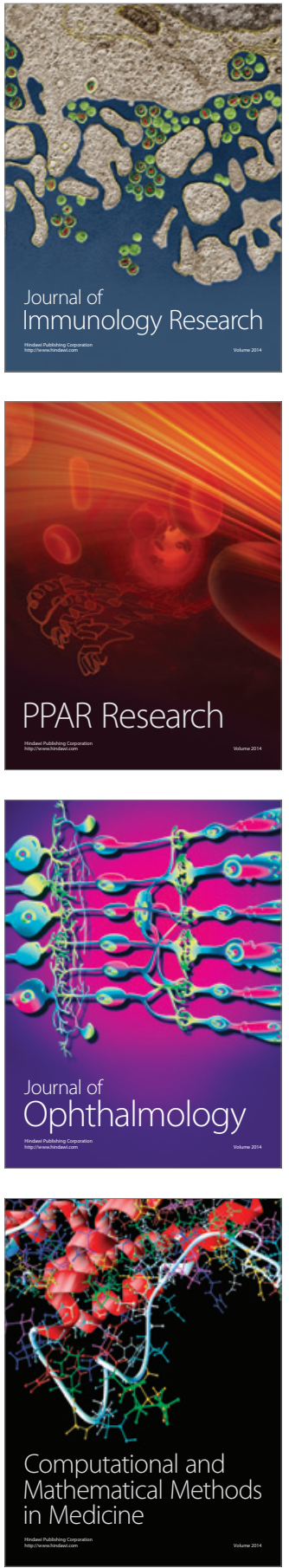

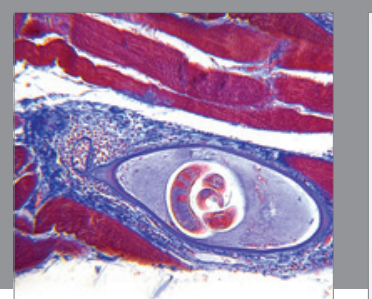

Gastroenterology Research and Practice

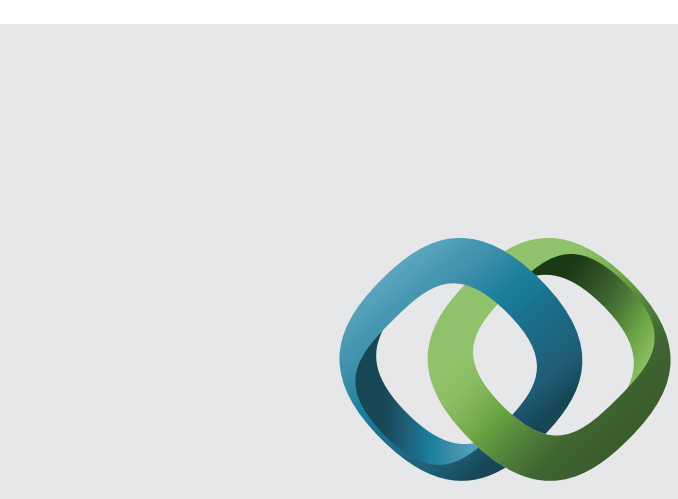

\section{Hindawi}

Submit your manuscripts at

http://www.hindawi.com
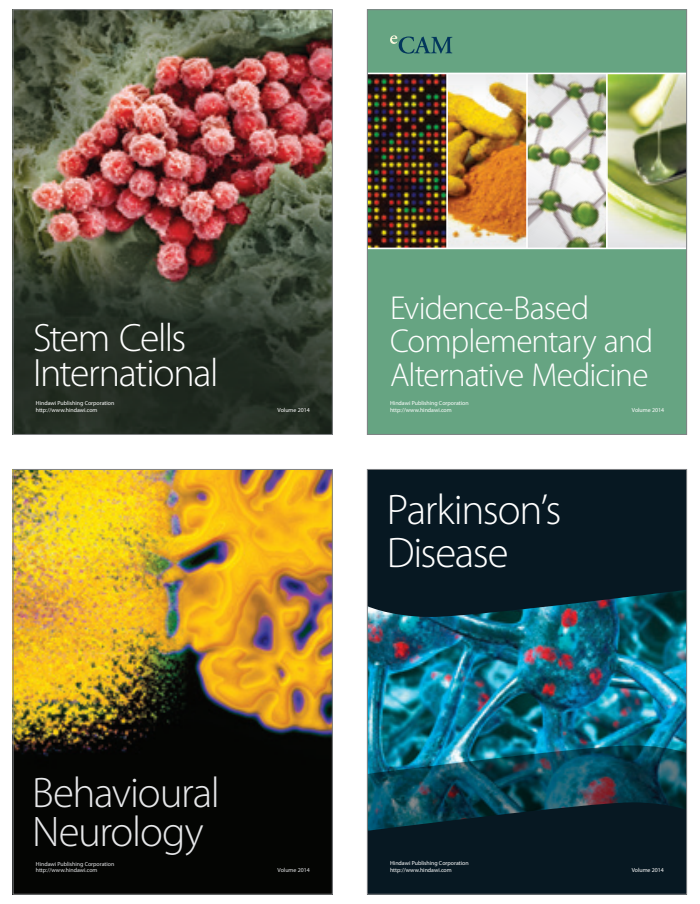
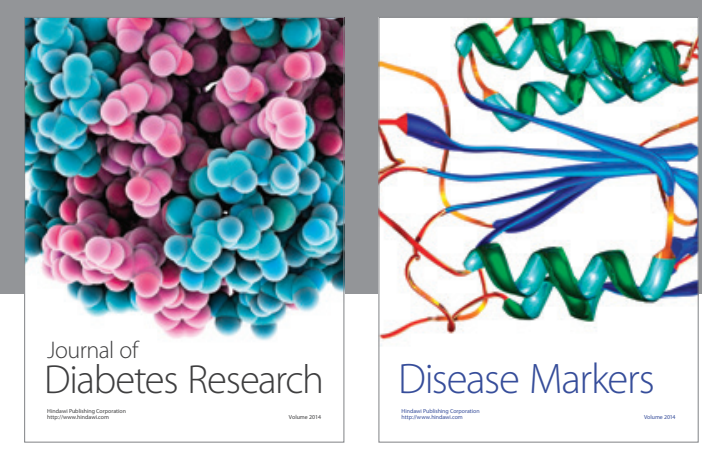

Disease Markers
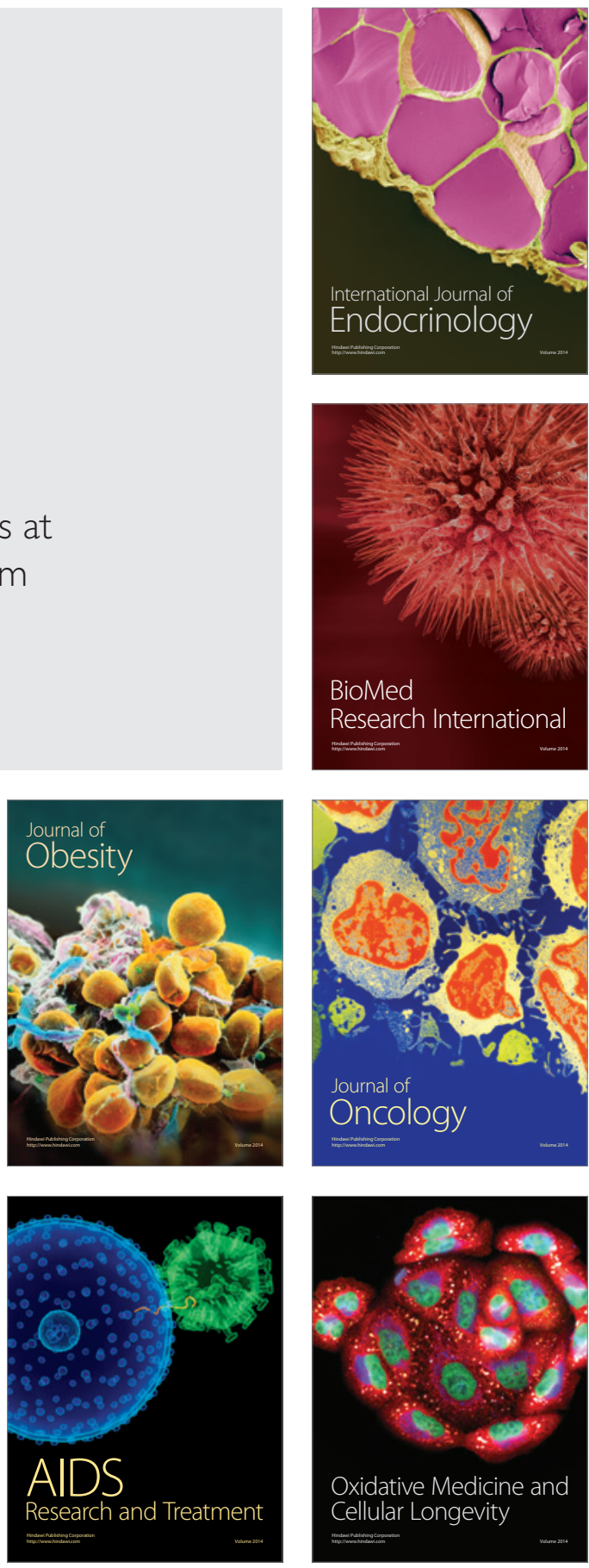